\title{
Metode Beda Hingga untuk Penyelesaian Persamaan Diferensial Parsial
}

\author{
Ikhsan Maulidi \\ Jurusan Matematika,Universitas Syiah Kuala, ikhsanmaulidi@rocketmail.com
}

\begin{abstract}
Artikel ini membahas tentang salah satu metode numerik untuk menyelesaian persamaan diferensial parsial yaitu metode beda hingga. Di bagian awal disajikan tentang dasar dasar dalam persamaan diferensial parsial, kemudian formulasi metode beda hingga, dan ditutup dengan contoh sederhana penerapan metode beda hingga dalam menyelesaikan persamaan adveksi yang banyak digunakan dalam memodelkan masalah transpor polu$\tan$.
\end{abstract}

\section{Pendahuluan}

Persamaan diferensial parsial (PDP) adalah persamaan diferensial yang memiliki dua atau lebih variabel bebas. Berikut contoh persamaan diferensial parsial

$$
a(t, x, y) U_{t}+b(t, x, y) U_{x}+c(t, x, y) U_{y y}=f(t, x, y)
$$

Keterangan:

- $t, x, y$ adalah variabel bebas.

- $a, b, c$, dan $f$ adalah fungsi yang bergantung pada variabel bebas dan diketahui.

- $U$ adalah variabel tak bebas dan fungsi yang belum diketahui.

- $u_{t}, U_{x}, U_{y y}$ adalah turunan-turunan parisal dari $U$.

Order dari suatu PDP adalah orde dari turunan parsial tertingginya. PDP dikatakan linear jika $U$ dan turunan-turunan parsial nya memiliki hubungan linear. Dimensi dari suatu PDP adalah banyaknya variabel bebas spasial.

Sebagai contoh pada persamaan (1) adalah PDP orde 2 (turunan parsial tertingginya adalah $U_{y y}$ ), linear, dan berdimensi 2 (ada 2 variabel spasial yaitu $x$ dan $y)$. 


\section{Solusi dan beberapa model PDP}

Solusi dari PDP dapat berupa solusi analitik (eksak) dan solusi numerik (aproksimasi). Solusi analitik adalah fungsi yang memenuhi PDP dan syarat batas dan/atau syarat nilai awal pada PDP. Sedangkan solusi numerik (analitik) dibuat pada nilai diskret dari variabel bebas berupa grid (mesh) dan diimplementasikan dalam program komputer.

Model-model dalam PDP banyak mendeskripsikan fenomena fisik, diantaranya:

i Persamaan Laplace, digunakan untuk memodelkan kestabilan konduksi panas.

ii Persamaan diferensial adveksi, untuk memodelkan transpor polutan.

iii Persamaan Maxwell, untuk memodelkan gelombang elektromagnetik.

iv Persamaan Navier-Stokes. untuk memodelkan aliran fluida.

\section{Masalah Nilai Batas dan Masalah Nilai Awal}

Suatu PDP dikatakan well-posed problem jika memiliki nilai awal (IC) atau nilai batas (BC) fungsi dan memiliki solusi yang tunggal. Terlalu banyak masalah nilai IC/BC yang diberikan akan menyebabkan solusi tidak ada. Namun jika terlalu sedikit dapat menyebabkan solusi tidak tunggal. Jika IC/BC diberikan pada daerah yang yang salah atau di variabel waktu yang salah maka solusi tidak akan bergantung pada IC/BC tersebut, dan sedikit kesalahan dalam IC/BC akan menyebabkan perubahan solusi yang besar. Masalah ini dikenal sebagai ill-posed problem.

\section{Klasifikasi PDP}

PDP orde 2 dapat diklasiikasikan dalam 3 tipe: Eliptik, Parabolik, dan hiperbolik. Berikut contoh contoh dari tipe-tipe tersebut:

a PDP Eliptik : $U_{x x}+U_{y y}=f(x, y)$, persamaan ini disebut persamaan Poisson, jika $f(x, y)=0$ maka disebut persamaan Laplace. Persamaan ini digunakan untuk memodelkan kestabilan penyebaran suhu di bidang atau aliran potensial 1D incompressible. Persamaan ini memerlukan nilai batas di setiap titik di batas. Nilai batas dapat berupa nilai $U$ atau turunan $U$ di batas.

b PDP Parabolik : $U_{t}=k U_{x x}$, Model persamaan difusi 1D, biasanya digunakan untuk model penyebaran suhu yang bergantung waktu sepanjang garis 1D. Persamaan ini memerlukan IC di waktu awal $(t=0)$ dan satu BC di akhir titik domain spasial. 
c PDP Hiperbolik: $U_{t t}=k U_{x x}$, persamaan ini merupakan persamaan gelombang, dapat digunakan untuk memodelkan getaran pada tali gitar atau airan supersonik 1D.

\section{Notasi Diskret}

Dalam catatan ini digunakan huruf $U$ besar untuk menyatakan solusi analitik dan huruf $u$ untuk menyatakan solusi aproksimasimasi. $u_{i, j}^{n}$ menyatakan solusi numerik di grid $(x, y)$ di daerah 2D pada level waktu $n$.

\section{Pemeriksaan hasil}

Sebelum mengaplikasikan skema numerik pada masalah real yang dimodelkan dengan PDP, ada 2 langkah penting yang perlu dilakukan, yaitu:

1. Verifikasi, adalah pemeriksaan apakah program melakukan apa yang diharapkan dengan mencoba membandingkan dengan hasil hitungan pulpen dengan hasil komputasi untuk bilangan yang kecil. Verifikasi dapat pula dilakukan dengan membandingkan solusi yang diperoleh dengan solusi analitik yang diperoleh .

2. Validasi, dilakukan dengan membandingkan hasil dengan kondisi dalam situsi real apakah hasil numerik yang diperoleh dapat menggambarkan dengan baik fenomena real. Hasil real diperoleh dengan melakukan percobaan dalam laboratorium.

\section{Penurunan Formula}

Metode beda hingga bekerja dengan merubah daerah variabel bebas menjadi grid berhingga yang disebut mesh dimana variabel dependen diaproksimasi. Berikut diberikan konstruksi dari penurunan formula beda hingga.

Misalkan $U$ adalah fungsi bergantung pada $x$ dan $t$. Dengan menggunakan formula Taylor, akan dikonstruksi turunan parsial $U$ terhadap $x$.

$U\left(t, x_{0}+\Delta x\right)=U\left(t, x_{0}\right)+\Delta x U_{x}\left(t, x_{0}\right)+\frac{\Delta x^{2}}{2 !} U_{x x}\left(t, x_{0}\right)+\ldots+\frac{\Delta x^{n-1}}{(n-1) !} U_{n-1}\left(t, x_{0}\right)+O\left(\Delta x^{n}\right)$.

Dengan memangkas (2) pada $O\left(\Delta x^{2}\right)$ diperoleh

$$
U\left(t, x_{0}+\Delta x\right)=U\left(t, x_{0}\right)+\Delta x U_{x}\left(t, x_{0}\right)+O\left(\Delta x^{2}\right)
$$


Dari persamaan (3) diperoleh

$$
U_{x}\left(t, x_{0}\right)=\frac{U\left(t, x_{0}+\Delta x\right)-U\left(t, x_{0}\right)}{\Delta x}-O(\Delta x) .
$$

Dalam skema numerik, variabel $x$ dipartisi menjadi diskret yang disebut grid, $x_{1}, x_{2}, \ldots, x_{N}$ dan $t$ dipartisi pada level $0=t_{0}, t_{1}, t_{2}, \ldots, t_{M}$. Jika $\Delta x$ diasumsikan konstan dan $x_{i+1}=x_{i}+\Delta x$, maka dari (4) diperoleh

$$
U_{x}\left(t_{n}, x_{i}\right)=\frac{U\left(t_{n}, x_{i+1}\right)-U\left(t_{n}, x_{i}\right)}{\Delta x}-O(\Delta x) .
$$

Dengan mengabaikan bentuk $O(\Delta x)$ sebagai bentuk error. Kita peroleh

$$
U_{x}\left(t_{n}, x_{i}\right) \approx \frac{U\left(t_{n}, x_{i+1}\right)-U\left(t_{n}, x_{i}\right)}{\Delta x}
$$

Bentuk (6) disebut aproksimasi beda maju orde 1 untuk $U_{x}\left(t_{n}, x_{i}\right)$. Selanjutnya dengan mengganti $\Delta x$ menjadi $-\Delta x$ pada (2) diperoleh

$$
U_{x}\left(t, x_{0}\right)=\frac{U\left(t, x_{0}\right)-U\left(t, x_{0}-\Delta x\right)}{\Delta x}+O(\Delta x) .
$$

Dengan mengevaluasi di $\left(t_{n}, x_{i}\right)$ dan melakukan aproksimasi pada (7) diperoleh

$$
U_{x}\left(t_{n}, x_{i}\right) \approx \frac{U\left(t_{n}, x_{i}\right)-U\left(t_{n}, x_{i-1}\right)}{\Delta x}
$$

Bentuk (8) dikenal sebagai aproksimasi beda mundur orde 1 untuk $U_{x}\left(t_{n}, x_{i}\right)$.

Selain bentuk (6) dan (8) kita juga dapat meningkatkan order aproksimasi agar lebih akurat dengan mengambil pemangkasan deret Taylor untuk $O\left(\Delta x^{3}\right)$ dari bentuk (2), dengan menggunakan $\Delta x$ dan $-\Delta x$,

$$
\begin{gathered}
U\left(t, x_{0}+\Delta x\right)=U\left(t, x_{0}\right)+\Delta x U_{x}\left(t, x_{0}\right)+\frac{\Delta x^{2}}{2 !} U_{x x}\left(t, x_{0}\right)+O\left(\Delta x^{2}\right), \\
U\left(t, x_{0}-\Delta x\right)=U\left(t, x_{0}\right)-\Delta x U_{x}\left(t, x_{0}\right)+\frac{\Delta x^{2}}{2 !} U_{x x}\left(t, x_{0}\right)-O\left(\Delta x^{3}\right) .
\end{gathered}
$$

Dengan mengurangkan persamaan (9) dan (10) diperoleh

$$
U_{x}\left(t, x_{0}\right)=\frac{U\left(t, x_{0}+\Delta x\right)-U\left(t, x_{0}-\Delta x\right)}{2 \Delta x}-O\left(\Delta x^{3}\right) .
$$

Dengan melakukan aproksimasi bentuk $(11)$ di $\left(t_{n}, x_{i}\right)$ diperoleh persamaan beda pusat orde 2 sebagai berikut

$$
U_{x}\left(t_{n}, x_{i}\right) \approx \frac{U\left(t_{n}, x_{i+1}\right)-U\left(t, x_{i-1}\right)}{2 \Delta x}
$$


Kita dapat pula mengkonstruksi turunan parsial untuk orde lebih tinggi dengan melakukan pemangkasan untuk $O\left(\Delta x^{4}\right)$ dan dengan menggunakan $\Delta x$ dan $\Delta x$.

$U\left(t, x_{0}+\Delta x\right)=U\left(t, x_{0}\right)+\Delta x U_{x}\left(t, x_{0}\right)+\frac{\Delta x^{2}}{2 !} U_{x x}\left(t, x_{0}\right)+\frac{\Delta x^{3}}{3 !} U_{x x x}\left(t, x_{0}\right)+O\left(\Delta x^{4}\right)$.

$U\left(t, x_{0}+\Delta x\right)=U\left(t, x_{0}\right)-\Delta x U_{x}\left(t, x_{0}\right)+\frac{\Delta x^{2}}{2 !} U_{x x}\left(t, x_{0}\right)-\frac{\Delta x^{3}}{3 !} U_{x x x}\left(t, x_{0}\right)+O\left(\Delta x^{4}\right)$.

Dengan menambahkan persamaan (13) dan (14) dan dengan melakukan aproksimasi diperoleh

$$
U_{x x}\left(t_{n}, x_{i}\right)=\frac{U\left(t_{n}, x_{i+1}\right)-2 U\left(t_{n}, x_{i}\right)+U\left(t_{n}, x_{i-1}\right)}{\Delta x^{2}} .
$$

Untuk pembahasan selanjutnya kita akan menggunakan simbol $U_{i}^{n}$ untuk menyatakan $U\left(t_{n}, x_{i}\right)$, atau

$$
U_{i}^{n}=U\left(t_{n}, x_{i}\right) .
$$

Dari penurunan di atas kita dapat memperoleh tabel berikut yang akan membantu kita dalam mengggunakan metode beda hingga. 


\begin{tabular}{|c|c|c|}
\hline \multicolumn{3}{|c|}{ Beberapa formula metode beda hingga } \\
\hline Turunan Parsial & $\begin{array}{ll}\text { Aproksimasi } & \text { Beda } \\
\text { Hingga } & \\
\end{array}$ & Tipe dan Orde \\
\hline$\frac{\partial U}{\partial x}=U_{x}$ & $\frac{U_{i+1}^{n}-U_{i}^{n}}{\Delta x}$ & Beda Maju 0orde 1 \\
\hline$\frac{\partial U}{\partial x}=U_{x}$ & $\frac{U_{i}^{n}-U_{i-1}^{n}}{\Delta x}$ & Beda Mundur orde 1 \\
\hline$\frac{\partial U}{\partial x}=U_{x}$ & $\frac{U_{i+1}^{n}-U_{i-1}^{n}}{2 \Delta x}$ & Beda pusat orde 2 \\
\hline$\frac{\partial^{2} U}{\partial x^{2}}=U_{x x}$ & $\frac{U_{i+1}^{n}-2 U_{i}^{n}+U_{i-1}^{n}}{\Delta x^{2}}$ & $\begin{array}{l}\text { turunan parsial } \\
\text { spasial ke } 2\end{array}$ \\
\hline$\frac{\partial U}{\partial t}=U_{t}$ & $\frac{U_{i}^{n+1}-U_{i-1}^{n}}{\Delta t}$ & Beda maju orde 1 \\
\hline$\frac{\partial U}{\partial t}=U_{t}$ & $\frac{U_{i}^{n}-U_{i}^{n-1}}{\Delta t}$ & Beda mundur orde 1 \\
\hline$\frac{\partial U}{\partial t}=U_{t}$ & $\frac{U_{i}^{n+1}-U_{1}^{n-1}}{2 \Delta t}$ & Beda pusat orde 2 \\
\hline$\frac{\partial^{2} U}{\partial t^{2}}=U_{t t}$ & $\frac{U_{i}^{n+1}-2 U_{i}^{n}+U_{i}^{n-1}}{\Delta t^{2}}$ & $\begin{array}{l}\text { turunan parsial } \\
\text { temporal ke } 2\end{array}$ \\
\hline
\end{tabular}

\section{Contoh Sederhana Skema Beda Hingga}

Misalkan diberikan persamaan adveksi linear berikut

$$
U_{t}+v U_{x}=0,
$$


dengan variabel bebas $x$ dan $t, x$ menyatakan ruang dan $t$ menyatakan waktu. Misalkan $x$ berada di $[p, q]$ yang disebut domain komputasi. $v$ adalah konstanta dan variabel dependen $U=U(x, t)$.

Dalam menyelesaikan masaah ini kita memerlukan kondisi awal

$$
U(0, x)=f(x), \quad p \leq x \leq q
$$

dengan $f(x)$ diketahui.

Solusi dari masalah (16) dan (17) adalah fungsi yang memenuhi (16) di semua domain komputasi $x$ dan semua $t$ di kondisi awal. $U(x, t)$ adalah solusi eksak yang terdefinisi pada takhingga titik $(t, x)$. Selanjutnya kita akan mengaproksimasi $U(x, t)$ dengan Metode Beda Hingga pada himpunan berhingga yang dinotasikan dengan $u$.

\subsection{Langkah 1 : Diskretisasi variabel spasial}

Misalkan kita membagi $[p, q]$ dalam $N$ grid, $x_{1}, x_{2}, \ldots x_{N}$, dengan mengambil $\Delta x$ yang sama,

$$
\Delta x=\frac{q-p}{N-1}
$$

- Selanjutnya kita punya $x_{1}=p, x_{2}=p+\Delta x, x_{3}=p+2 \Delta x$, dst sampai $x_{N}=$ $p+(N-1) \Delta x=q$.

Dengan menetapkan untuk $t=t_{n}$, kita dapat menghampiri $U_{x}$ pada setiap titik $\left(t_{n}, x_{i}\right)$ dengan menggunakan formula beda maju

$$
U_{x}\left(t_{n}, x_{i}\right) \approx \frac{U_{i+1}^{n}-U_{i}^{n}}{\Delta x}
$$

Dengan menyubstituikan (18) ke (16) kita peroleh persamaan berikut

$$
U_{t}+v \frac{U_{i+1}^{n}-U_{i}^{n}}{\Delta x}=0 .
$$

Bentuk (19) disebut juga bentuk semi diskret karena hanya variabel spasial yang didiskretisasi.

\subsection{Langkah 2: Diskretisasi variabel waktu $(t)$}

Dengan menetapkan $x$ di $x=x_{i}$, kita dapat mengaproksimasi turunan parsial terhadap variabel waktu (turunan parsial temporal) $U_{t}$ di setiap titik $\left(t_{n}, x_{i}\right)$ menggunakan formula beda maju orde 1

$$
U_{t} \approx \frac{U_{i}^{n+1}-U_{i}^{n}}{\Delta t}
$$


Selanjutnya dengan menyubstitusikan (20) ke (19) diperoleh

$$
\frac{U_{i}^{n+1}-U_{i}^{n}}{\Delta t}+v \frac{U_{i+1}^{n}-U_{i}^{n}}{\Delta x}=0
$$

yang memberikan

$$
U_{i}^{n+1}=U_{i}^{n}-\frac{v \Delta t}{\Delta x}\left(U_{i+1}^{n}-U_{i}^{n}\right) .
$$

Persamaan (21) merupakan contoh penerapan skema beda hingga untuk mengaproksimasi solusi dari PDP (16) yang disebut skema baris waktu (time-marching) karena nilai $U$ di level waktu selanjutnya dapat diaproksimasi dengan nilai $U$ di level waktu $n$. Karena semua nilai $U$ hanya diketahui secara eksak di level waktu awal, maka bentuk (21) dapat ditulis

$$
u_{i}^{n+1}=u_{i}^{n}-\frac{v \Delta t}{\Delta x}\left(u_{i+1}^{n}-u_{i}^{n}\right),
$$

dimana $u_{i}^{n}$ adalah aproksimasi dari $U_{i}^{n}=U\left(t_{n}, x_{i}\right)$.

Beberapa catatan:

1. $u(0, x)=U(0, x)$, tapi ini tidak selalu berlaku.

2. Error dari aproksimasi turunan parsial spasial dan turunan parsial temporal pada (22) adalah $O(\Delta x)$ dan $O(\Delta t)$ yang secara formal disebut orde 1 di ruang $x$ dan orde satu di waktu $(t)$.

3. Semakin besar $N$ akan menyebabkan $\Delta x$ semakin kecil dan diharapkan hampiran akan semakin baik. Namun semakin besar $N$ akan menyebabkan kecepatan komputasi akan semakin menurun. Sehingga perlu dipertimbangkan antara akurasi dan kecepatan.

4. Bentuk (22) disebut juga metode eksplisit karena nilai $u$ di level waktu selanjutnya dapat diberikan dalam formula eksplisit.

\section{Perhitungan dengan Pulpen dan Kertas}

Dalam melakukan skema numerik kita perlu mencoba melakukan perhitungan dengan pulpen dan kertas sebelum mengimplementasikan dalam bahasa pemrograman. Hal ini karena kita perlu

1. Memahami skema numerik yang akan dijalankan.

2. Memeriksa hasil dari program komputer dengan hasil perhitungan yang kita peroleh menggunakan pulpen dan kertas. 


\section{Contoh:}

Misalkan dalam contoh sebelumnya, $p=0, q=100, v=0.5$, dan diberikan kondisi awal

$$
U(0, x)= \begin{cases}e^{-0.01(x-45)^{2}} & 20 \leq x \leq 70 \\ 0 & \text { lainnya }\end{cases}
$$

Misalkan banyaknya grid $N=11$, maka

$$
\Delta x=\frac{100-0}{11-1}=10 \text {. }
$$

Akibatnya nilai $x$ berkorespondensi dengan grid $0,10,20, \ldots 100$ dan misalkan $\Delta t=$ 3, maka persamaan (22) menjadi

$$
u_{i}^{n+1}=u_{i}^{n}-0.15\left(u_{i+1}^{n}-u_{i}^{n}\right) .
$$

Pada $t=0$ kita dapat menggunakan kondisi awal (23). Sehingga dengan menggunakan bentuk (24) kita peroleh

$$
u_{i}^{1}=u_{i}^{0}-0.15\left(u_{i+1}^{0}-u_{i}^{0}\right) .
$$

Selanjutnya dengan mengevaluasi untuk beberapa grid ke- $i, i=1,2,3,4,5$ dari variabel spasial diperoleh

$$
\begin{gathered}
u_{1}^{0}=u\left(0, x_{1}\right)=u(0,0)=0, \\
u_{2}^{0}=u\left(0, x_{2}\right)=u(0,10)=0, \\
u_{3}^{0}=u\left(0, x_{3}\right)=u(0,20)=e^{-0.01(20-45)^{2}}=0.0019, \\
u_{4}^{0}=0.1054, \\
u_{5}^{0}=0.7788 .
\end{gathered}
$$

Selanjutnya dengan menggunakan formula (25)

$$
\begin{gathered}
u_{1}^{1}=u_{1}^{0}-0.15\left(u_{2}^{0}-u_{1}^{0}\right)=0-0.15(0-0)=0 \\
u_{2}^{1}=u_{2}^{0}-0.15\left(u_{3}^{0}-u_{2}^{0}\right)=0-0.15(0.0019-0)=-0.00029 \\
u_{3}^{1}=-0.01363 .
\end{gathered}
$$

Permasalahan yang muncul dalam metode beda maju untuk turunan parsial spasial ini adalah ketika kita akan mengevaluasi nilai di batas yaitu untuk $i=11$ dalam contoh ini, dimana formula (22) membutuhkan grid berikutnya $i=12$ yang tidak diketahui. Sehingga kita perlu mendefinisikan titik bantu yang disebut titik hantu (ghost point). Contoh dalam kasus ini kita bisa menggunakan $x_{12}=$ 110 (tidak selalu berlaku) dan asumsi $u_{12}^{n}=u_{1}^{n} 11, n=0,1,2, \ldots$, sehingga kita bisa mengevaluasi nilai di batas sebagai berikut,

$$
\begin{aligned}
& u_{11}^{1}=u_{11}^{0}-0.15\left(u_{12}^{0}-u_{11}^{0}\right)=0-0.15(0-0)=0, \\
& u_{11}^{2}=u_{11}^{1}-0.15\left(u_{12}^{1}-u_{11}^{1}\right)=0-0.15(0-0)=0,
\end{aligned}
$$

dan seterusnya. 


\section{References}

[1] Ames, W.F., 1977, Numerical Methods for Partial Differential Equations (second Ed.), Academic Press.

[2] Butcher, C., 2008, Numerical Methods for Ordinary Differential Equation, 2nd Edition, John Wiley and Sons, Ltd., West Sussex, England

[3] D.D Causon, C.G Mingham, 2010, introductory Finite Difference Methods for PDEs, Ventus Publishing Aps,ISBN 978-87-7681-642-1.

[4] Lapidus, L. dan Seinfeld, J.H., 1971, Numerical Solution of Ordinary Differential Equation, Academic Press Inc., New York, USA.

[5] Morton, K.W., Mayers, D, 2005, Numerical Solution of Partial Diferential Equations, 2nd Ed., Cambridge University Press, UK. 